\title{
Study on the Innovative Talents Cultivation Model of English Majors Under the Background of "New Liberal Arts"
}

\author{
Xiaoming $\mathrm{YaO}^{1}$ \\ ${ }^{1}$ School of Foreign Studies, Zhongyuan University of Technology, Zhengzhou, China \\ Email:3451@zut.edu.cn
}

\begin{abstract}
The "New Liberal Arts Declaration" puts forward the policy of "proactively seeking change, innovative development". Based on the background of new liberal arts education, this article explores the innovative path of English talent cultivating model, including integration of "curriculum ideological and political education" and "ideological and political course", interdisciplinary integration, "3M+3C+3I" three-dimensional talent cultivating model, smart learning platform and English professional talent cultivating evaluation system, aiming to cultivate compound talents with firm political beliefs, broad international vision, solid language skills, and interdisciplinary backgrounds to serve the country's "four comprehensive" strategy , "One Belt, One Road" initiative and the construction of "Three Districts and One Group" in Henan Province.
\end{abstract}

Keywords : new liberal arts, innovative path, cultivating model, English major

\section{INTRODUCTION}

"New Liberal Arts" was proposed by Hiram College of the United States in 2017. It refers to the reorganization of traditional liberal arts, the intersection of liberal arts and sciences, and the integration of new technologies into philosophy, literature, language and other courses, providing students with comprehensive interdisciplinary Knowledge learning [1]. On April 29, 2019, 13 departments including the Ministry of Education, the Central Political and Legal Affairs Commission, and the Ministry of Science and Technology jointly launched the Six Excellence \& One Top Plan 2.0 in Tianjin to comprehensively promote the construction of new engineering, new medical, new agricultural, and new liberal arts. China Major media such as Social Science News, China Education News, Guangming Daily, and Social Science News successively published a series of articles on "New Liberal Arts", which defined the meaning of it, clarified the significance of the construction of it, and proposed the implementation path and method of liberal arts construction. The concept of new liberal arts is relative to the traditional liberal arts. It is based on the global new technological revolution, new economic development, and the new era of socialism with Chinese characteristics as the background. It breaks through the traditional liberal arts thinking mode, promoting interdisciplinary and in-depth integration and the upgrading of traditional liberal arts by heritage and innovation, intercrossing and syncretization, synergism and sharing [2]. At present, English majors generally have a series of problems such as over-positioning, out of touch with the actual needs of regional economic development, vague orientation of talent cultivation, the same basic requirements, and lack of outstanding characteristics. Based on these, it is a tendency for foreign language colleges and universities to explore the reform model of talent cultivation. This article studies how English majors can get rid of the instrumental rationality of "English majors are the majors for learning English" and the value rationality of "uselessness" of humanities [3], and talk about what kind of people and for whom English majors should cultivate in the new era. With the changes under the new situation, English majors should seek greater development opportunities in the reform, and cultivate talents that will meet the targeted development in the face of China's economy and culture to "go global", and to build a community with a shared future for mankind. All kinds of professional technical and management talents who know foreign languages that are urgently 
needed in the construction of national development strategies are the cultivating goals of English majors [4].

\section{THE CONNOTATION OF THE CULTIVATION GOAL OF ENGLISH MAJOR TALENTS UNDER THE BACKGROUND OF THE NEW LIBERAL ARTS}

Over the past 40 years of reform and opening up, the exploration of the cultivation model for English majors has been the focus of general and continuous attention in the foreign language education community. However, there are still relatively a few domestic theoretical researches on the construction of "new liberal arts", and practical exploration of the cultivating models for English majors. The interdisciplinary nature of the cultivating model for English majors is relatively inadequate, and it cannot fully adapt to the Chinese culture "going global" strategy and the "Belt and Road" initiative for the fundamental needs of interdisciplinary English talents, nor can it fully respond to the in-depth challenges brought by artificial intelligence. There are three common problems in the cultivating process of English majors: (1) Emphasize skills and neglect quality; (2) Emphasize profession and neglect general education; (3) Emphasize application and neglect culture. The new era and the new situation require the innovative development and modernization of higher liberal arts education. Only by actively responding to changes and reforming the English major can the cultivating model be implemented and the profound connotations of the new liberal arts education can be implemented. The National Standards for the Quality of Undergraduate Teaching for English Majors promulgated by the Ministry of Education in 2018 provides a programmatic guidance plan for English major education. The "National Standard" specifies the objectives and specifications for the cultivation of English professionals at three levels: literacy, ability and knowledge. At the level of literacy, the "National Standards" proposes that students should establish a correct world view and rational qualities; while having an international perspective, they should have family and country feelings, a sense of social responsibility, humanities and science literacy, innovative spirit and basic academic literacy. At the knowledge level, the "National Standard" requires English majors to master English language knowledge, English literature knowledge, regional country knowledge, familiar with Chinese language and culture knowledge, understand related majors, humanities, social sciences and natural sciences, and form an interdisciplinary knowledge structure. Reflect professional characteristics. At the level of ability, the "National Standard" requires English majors to have the ability to use English language, literary appreciation, cross-cultural ability, speculative ability, as well as certain research ability, innovation ability, information technology application ability, independent learning ability and practical ability. This article is guided by the construction of "New Liberal Arts" and the "New Mission, Grand Pattern, New Liberal Arts, large Foreign Languages", a theme report of "Foreign Language" by Wu Yan, Director of the Ministry of Education, attempting to answer the following questions: How to build a cultivating model for English professionals to serve the national strategic development and local regional economic development? How to implement the basic concept of "morality first" education to implement the fundamental task of fostering English professionals and strengthening moral cultivation? How to position the cultivating goal and talent cultivating model of English majors around the fundamental principles of "what kind of talents to cultivate, how to cultivate and for whom to cultivate in education in the new era"? Through research and practice, a perfect new liberal arts talent cultivating model with distinctive characteristics has been constructed, and a compound foreign language talent with strong political beliefs, broad international perspectives, solid language skills, and interdisciplinary backgrounds will be cultivated to serve national development strategy and the construction of a community with a shared future for mankind.

\section{INNOVATIVE PATH OF CULTIVATING MODEL OF ENGLISH TALENTS}

Sun Youzhong put forward: "If a university English undergraduate major turns about $70 \%$ of the class hours into language cultivating, then this major loses its legitimacy as a university subject education. [5]" With the "Belt and Road" initiative, and the proposal of "going global" in Chinese culture and building a community of shared future for mankind, the society's demand for English professionals has undergone essential changes [6]. The development of new liberal arts requires that the construction of English majors in colleges and universities should be cross-integrated in accordance with the development of national strategies.

\subsection{Innovative integration of "curriculum ideological and political education" and "ideological and political course"}

Supporting the construction of a first-class country with first-class talents is the basic logic for the rise of a powerful country. The hard power and soft power of the country's innovation and development all depend on the strength of talents [7]. Under the background of "new liberal arts", In order to cultivate first-class English talents meeting national strategies, English majors need to think about what kind of talents to train and how to train high-quality talents. Relying on the school-based "English Discipline +" characteristic carrier, our 
university stimulates the internal drive of teachers' curriculum ideological and political education and ideological and political course. Give full play to the characteristics and advantages of English majors, make full and larger "English majors +" articles, and integrate ideological and political education into the talent cultivating system. Re-examine, evaluate and improve the cultivating plan, curriculum system, teaching mode and teaching evaluation system of English majors, create a smart learning platform, increase the research and development of characteristic teaching resources, and strengthen the theoretical courses of English majors. The construction of "golden courses" with practical courses, strengthen practical education, and strengthen innovation and entrepreneurship education. Incorporate ideological and political elements into the two modernizations, two courses and Innovation and Entrepreneurship projects to solve the above problems of "what kind of talents to cultivate, how to cultivate and for whom to cultivate in education in the new era".

\subsection{Interdisciplinary integration and interdisciplinary English talents cultivation}

In today's building of a community with a shared future for mankind, intercultural communication skills have become an indispensable key quality in international communication. Facing the new requirements of national economic and social development and international exchanges and cooperation, English majors in universities should continue to expand their professional perspectives, deepen educational reforms, and devote themselves to the cultivation of interdisciplinary talents in order to better adapt to the new era of foreign language talents [8]. Re-establish the types, position and goals of talent cultivation in accordance with the National Standards, clarify cultivating specifications from the three dimensions of quality, ability and knowledge, and improve the whole-person cultivating model of teaching with a knowledge system, cultivating with a value system, and doing with an innovation system. In the professional cultivating, increase the construction of modular, international, and individualized curriculum groups with distinctive characteristics, and cultivate compound and international talents with sound personality and professional knowledge, international vision and cultural awareness, innovative spirit and practical ability. Our faculty cooperated with the Intellectual Property Publishing House to establish a patent translation cultivating base to jointly cultivate English + technology + legal talents; to develop school-enterprise cooperation with Waiyan Xunfei Education Technology Co., Ltd. to effectively use school-enterprise cooperation resources through the realization of open collaborative innovation. Reorganize the cultivating of traditional English majors, actively explore ways of integrating and intersecting English majors with other majors, advocating the intersection of liberal arts and sciences and comprehensive interdisciplinary learning, and promoting the construction of cross-module cultivating courses. In terms of discipline layout, strengthen the top-level design, promote interdisciplinary integration on the basis of maintaining the development of traditional English disciplines, and accelerate the cultivation of new discipline growth points, so as to promote the overall improvement of the discipline and the optimization of the layout. Facing the future, the layout and construction of cutting-edge and interdisciplinary fields represented by "English + Intellectual Property, English + Accounting, English + Economics" and "International and Regional Studies" will drive the optimization and adjustment of the discipline structure and cultivate high-level compound English talents.

\subsection{Three-dimensional talent cultivating model of " $3 M+3 C+3 I$ construction}

Professional characteristics should be found from the interdisciplinary nature and openness of English major, and the concept of professional development should be updated, the talent cultivating model should be innovated, the talent cultivating program should be optimized, and the intelligent technology should be deeply integrated with foreign language education and teaching. Global competence is a comprehensive literacy in the era of economic globalization, and it is also a 21 st century civic literacy based on bilingual and even multilingual abilities, integrating knowledge, skills, attitudes and values. Therefore, building a three-dimensional talent cultivating model of " $3 \mathrm{M}+3 \mathrm{C}+3 \mathrm{I}$ " is an important content of this research. 3M means "content interdisciplinarity, curriculum modularization, and information multi-dimensionality", 3C means the cultivating process focuses on "construction, cooperation, and communication", 3I means teaching management and evaluation "interaction, impartial, and internationalization" to help students learn and master knowledge of English. It forms the emotions, attitudes and values needed to build a community with a shared future for mankind, and develops global competence [9]. Based on school-based artificial intelligence + , implement the reform of the "artificial intelligence +" project-driven patent translation talent cultivating model to meet the national strategic needs and the international needs of enterprises in Henan province to "going global".

\subsection{Smart learning platform construction}

According to the connotation of smart education and the principle of human-machine-environment matching, actively build a "five-dimensional one" wisdom education system, create a scientific wisdom education environment, create online and offline hybrid golden 
classes, and realize smart education. Establish an intelligent, network and digital interactive system to provide an open learning environment. It provides channels and platforms for communication and cooperation between teachers and students, students and students, and cleverly resolves the awkward relationship between traditional classrooms, and makes rigid classrooms active and stimulates the potential of every student. And to scientifically manage the process of students learning English, realize diversified course evaluation, build an intelligent management platform for cultivating students' independent learning ability and English expression ability. While cultivating students to have the ability to solve problems, stimulate innovation and creative thinking.

\subsection{Data-driven and model-driven evaluation system Integration}

The fusion characteristics of the new liberal arts educational concept not only include the integration of disciplines, but also the integration of new technologies. Cultivating talents by new pedagogy and digital technology are good examples to explain how Digital Humanities aid the construction of New Liberal Arts [10]. The cultivating and evaluation system of English talents under the background of information technology is a complex and dynamic system that needs to be studied with holism. Evaluation indicators should reflect the inherent characteristics of the education and the characteristics of the times. Using the method of combining qualitative evaluation and quantitative analysis, using relatively unified standards and appropriate weights, the index system is quantified, and the evaluation index system is rigorously structured and standardized and reasonable; the source of the evaluation is authentic and reliable, and the model is constructed to reflect the truth.

\section{CONCLUSION}

English major talent cultivation faced new problems under the background of new liberal arts construction. After bidding farewell to the era of language and skill teaching, English majors are turning to interdisciplinary education. The innovation of the cultivating model for English majors is an important starting point for colleges and universities to implement General Secretary Xi Jinping's important exposition on education and the spirit of the National Education Conference, and to implement the requirements of the National Undergraduate Education Work Conference in the New Era. According to their own positioning and characteristics, colleges and universities actively explore the path of cultivating English talents in the new era under the background of new liberal arts to cultivate targeted, internationalized, high-level, integrated English talents that the country urgently needs for meeting national and regional social and economic development.

\section{ACKNOWLEDGMENTS}

This article is the phased research results of the 2021 Henan Province's key scientific research project "Study on the Construction of Modern English Majors Cultivating Model under the Background of New Liberal Arts Education" (No. 21B880050).

\section{REFERENCES}

[1] Mai, K.S., Wang, H. (2018) An attempt at a new liberal arts. http://jwc.bjfu.edu.cn/jyjxwy/284335.html

[2] Wang, M.Y., Zhang, T. (2019) Thoughts and Explorations on the Construction of New Liberal Arts in Colleges and Universities-Also on the Construction of Foreign Languages and Literatures Discipline. Journal of Tianjin Foreign Studies University, 6:1-7.

[3] Zhang, X. (2020) New liberal arts, foreign language and English majors "holistic education" cultivating path. Foreign Languages, 5:14-18.

[4] Wu, Y. (2019) New Mission, Grand Pattern, New Liberal Arts, Large Foreign Language. Foreign Language Education in China, 2:3-7+90.

[5] Sun, Y. Z. (2017) Humanities English Education Theory. Foreign Language Teaching and Research, 6: 859-870.

[6] Wang, J. J. (2018) The formulation of the cultivating plan for English majors under the background of "National Standards"-Principles And path. Foreign Languages in China, 4: 4-10.

[7] Zhou, Y. Li, Z. Z. (2019) The rationale and design of new liberal arts construction. China University Teaching, 6: 52-59.

[8] Jiang, H. X. (2019) Thoughts on the cultivation of compound talents in foreign language majors in the new era. China Foreign Languages, 1: 11-14.

[2] Mei, D. M. (2018) Foreign language education in the new era should help build a "community with a shared future for mankind". http://news.shisu.edu.cn/research-/180228-035017

[10] Wang, L. H. Liu, W. (2021) Aiding and Leveraging: Digital Humanities VS the Construction of New Liberal Arts. Nanjing Journal of Social Sciences, 7:130-138. 